\title{
Effective SGLT2 Inhibitor for Patient with Type 2 Diabetes Mellitus (T2DM) and Depression
}

Shimizu $\mathrm{E}^{1}$, Takehisa $\mathrm{Y}^{1}$, Bando $\mathrm{H}^{1,2,3^{*}}$, Fujita $\mathrm{M}^{1}$, Kusaka $\mathrm{Y}^{1}$, Yuu $\mathrm{M}^{1}$

${ }^{1}$ Eto Hospital, Hakuai Group, Tokushima, Japan

${ }^{2}$ Medical Research/Tokushima University, Tokushima, Japan

${ }^{3}$ Japan Low Carbohydrate Diet Promotion Association (JLCDPA), Kyoto, Japan

Corresponding Author: Hiroshi BANDO, MD, PhD

Address: Medical Research/Tokushima University, Nakashowa 1-61, Tokushima 770-0943, Japan; Tel: +81-90-31872485, Fax: +81-88-6o3-1030; Email: pianomed@bronze.ocn.ne.jp

Received date: 20 March 2020; Accepted date: 6 April 2020; Published date: 14 April 2020

Citation: Shimizu E, Takehisa Y, Bando H, Fujita M, Kusaka Y, Yuu M. Effective SGLT2 Inhibitor for Patient with Type 2 Diabetes Mellitus (T2DM) and Depression. Diab Res Open Access. 2020 Apr 14;2(S1):26-32.

Copyright (C) 2020 Shimizu E, Takehisa Y, Bando H, Fujita M, Kusaka Y, Yuu M. This is an open-access article distributed under the Creative Commons Attribution License, which permits unrestricted use, distribution, and reproduction in any medium, provided the original work is properly cited.

\section{Abstract}

The case was a 55-year-old female patient with depression for 5 years and type 2 diabetes mellitus (T2DM) for 3 years. She has received anti-depressant and anti-hyperglycemic agents (OHAs). Approximately 1 year ago, her diabetic control became exacerbated without specific triggers. She was started to given Ipragliflozin L-Proline as Sodium-Glucose Cotransporter-2 (SGLT2) Inhibitor. After that, her glucose variability and depression had been improved. According to the previous reports, SGLT-2 inhibitors seem to have anti-depression efficacy for diabetes. The case has been followed up in detail, and this report is expected to be a useful reference for diabetes care.

\section{Keywords}

Sodium-Glucose Cotransporter-2 (SGLT2) Inhibitor; Ipragliflozin L-Proline; Depression; Oral Hypoglycemic Agents (OHA); Low-Carbohydrate Diet (LCD)

\section{Abbreviations}

T2DM: Type 2 Diabetes Mellitus; SGLT2: Sodium-Glucose Cotransporter-2; LCD: Low-Carbohydrate Diet; OHA: Oral Hyperglycemic Agents; DPP-4: Dipeptidyl Peptidase-4

\section{Introduction}

Diabetes mellitus has been one of the crucial diseases from medical and economical points of view [1]. It has been prevalent across the world including developed countries and also developing countries. For adequate glycemic control, there are some diabetic standard guidelines $[2,3]$.

Regarding the therapy of diabetes mellitus, nutritional treatment has been the fundamental treatment including various dietary methods such as calorie restriction (CR), Mediterranean diet, lowcarbohydrate diet (LCD) and so on [4]. LCD was initiated by Bernstein and other investigators in the North American region [5,6]. Successively in Japan, LCD was started and developed by author and colleagues so far through the Japan LCD promotion association (JLCDPA) [7,8].

Regarding the pharmaceutical aspect of diabetes, there have been recently several kinds of effective oral hyperglycemic agents (OHA). They include $\alpha$ - 
glucosidase inhibitors, glinides, dipeptidyl peptidase-4 (DPP-4) inhibitors and Sodium-Glucose Cotransporter-2 (SGLT2) inhibitors [9]. In particular, DPP-4 inhibitors and SGLT2 inhibitors have been in focus for clinical diabetic practice and research [2].

On the other hand, a certain relationship between type 2 diabetes mellitus (T2DM) and depression has been known for various studies [10]. The prevalence of depression in T2DM is lower in East Asia and higher in the US and Europe [10]. The ratio would be $10.6 \%$ in the US, $9.3 \%$ in the UK and $6.1 \%$ in China, and female cases show higher prevalence than male in each country [11-13].

T2DM has been suggested to be one of the risk factors for depressive state or depression [14]. Furthermore, both diabetes and depression have been independent risk factors for developing dementia [15]. Thus, these three factors would be highly risky for brain atrophy with hippocampal atrophy by brain MRI [16]. Consequently, it is crucial to prevent exacerbation of diabetes and depression.

Regarding the two topics mentioned above, there was a report related to OHA and depression in diabetic patients [9]. Among them, the influence of the administration of DPP-4 and SGLT2 inhibitors for developing depression are shown. These aspects would be meaningful for diabetes practice in the actual out clinic and primary care setting.

The authors have continued diabetic research for long in several axes [17]. They include a daily profile of blood glucose, $M$ value, continuous glucose monitoring (CGM), elevated ketone bodies, comparison of CR and LCD, elevated ketone bodies in fetus-placenta-pregnant woman-newborn, and so on $[18,19]$. During our diabetic practice and research, we have an impressive case associated with diabetes and depression. Then, we describe the case and some discussions in this article.

\section{Case}

\section{Present History:}

The case was a 55-year-old female patient with T2DM. She has diagnosed as a depressive state 5 years ago and has received anti-depressant agents. About 3 years ago, she was pointed out to have diabetes in another psychosomatic clinic. At that time, her data included moderate obesity, negative anti-GAD antibody, and T2DM as a diagnosis.

After that, her general status including depression and diabetes had been stable. Then she hoped to be treated at a nearer hospital and was introduced to our hospital.

\section{Physicals:}

We have evaluated her diabetes in detail. She has slight peripheral neuropathy in the hands and feet, no apparent retinopathy and stage 1 nephropathy. Regarding physical examination, she showed normal vital signs and unremarkable physical status (pulse 76, BP 112/77, SpO2 96\%), and no consciousness or feeling disorders from hyper- or hypoglycemia. She has moderate obesity, with the body mass index (BMI) $28.7 \mathrm{~kg} / \mathrm{m}^{2}$.

\section{Laboratory Exam:}

The data of the laboratory tests were in the following. The fundamental peripheral blood and biochemical data were: WBC $5100 / \mu \mathrm{L}, \mathrm{RBC} 4.31 \mathrm{x}$ $10^{6} / \mu \mathrm{L}, \mathrm{Hb} 13.6 \mathrm{~g} / \mathrm{dL}$, Plt $22.1 \times 10^{4} / \mu \mathrm{L}$, AST $20 \mathrm{IU} / \mathrm{mL}$, ALT $30 \mathrm{IU} / \mathrm{mL}$, ALP $197 \mathrm{IU} / \mathrm{mL}$ (100-340), LD 158 $\mathrm{IU} / \mathrm{mL}$ (100-210), T-Bil $0.5 \mathrm{mg} / \mathrm{dL}, \mathrm{BUN} 14 \mathrm{mg} / \mathrm{dL}$, Cre $0.8 \mathrm{mg} / \mathrm{dL}$, Uric Acid $5.4 \mathrm{mg} / \mathrm{dL}, \mathrm{Na} 141 \mathrm{mmol} / \mathrm{L}, \mathrm{K} 4.3$ $\mathrm{mmol} / \mathrm{L}, \mathrm{Cl} 104 \mathrm{mmol} / \mathrm{L}, \mathrm{HDL} 69 \mathrm{mg} / \mathrm{dL}$, LDL 155 $\mathrm{mg} / \mathrm{dL}$, TG $226 \mathrm{mg} / \mathrm{dL}$. Data related diabetes were HbA1c 6.7\%, pre-prandial glucose $184 \mathrm{mg} / \mathrm{dL}$. Urine analysis revealed negative for protein, sugar and ketone bodies.

\section{Detail Evaluation:}

From the data mentioned above, we have pointed out her medical problems. Her problem lists showed that \#1 T2DM, \#2 dyslipidemia (on anti-dyslipidemia agent), \#3 metabolic syndrome, \#4 osteoarthritis (OA) of the bilateral knees, \# 5 depression (slight).

\section{Clinical Progress:}

Successively, the same treatment had been continued and her HbA1c was stable at around 6.5\%. 
As to the medication, she had been provided metformin 1000mg, vildagliptin 100mg and Ezetimibe 10mg per day as the treatment of T2DM and dyslipidemia.

For the depressive status, she showed rather an unstable situation with depression, general malaise and sometimes suicide desire for years. She had been provided duloxetine hydrochloride (Cymbalta) 2omg in the morning as Serotonin and Noradrenaline Reuptake Inhibitor (SNRI), mirtazapine (Reflex) 15mg before sleep as Noradrenergic and Specific Serotonergic Antidepressant (NaSSA), and etizolam (Depas) 1.0 - $1.5 \mathrm{mg}$ per day as Benzodiazepine anxiolytics.

Approximately 1 year ago, her HbA1c value was suddenly elevated up to $7.9 \%$ without any special causes detected. Consequently, she was started to have Ipragliflozin L-Proline (Sugar) $25 \mathrm{mg}$ as an SGLT2 inhibitor. By the administration of SGLT2-I, her blood glucose and HbA1c values were decreased to a satisfactory degree. The progress of HbA1c value, urine sugar and the administration of anti-diabetic agents were shown in (Fig-1). HbA1c was reduced from $7.9 \%$ to $6.4 \%$ and urine sugar was increased after providing of Ipragliflozin.

After 1 year from the initiation of Ipragliflozin, lipid profile revealed that HDL $65 \mathrm{mg} / \mathrm{dL}$, LDL $110 \mathrm{mg} / \mathrm{dL}$,
TG $128 \mathrm{mg} / \mathrm{dL}$. Although there was not a quantitative evaluation for the degree of her depressive state, unstable psychiatric symptoms such as suicide desire have gradually disappeared after the starting of the Ipragliflozin administration.

\section{Discussion}

In recent diabetic practice, the spread of LCD and beneficial effects of SGLT2 inhibitors have been attracting attention. In the light of carbohydrates, the former is to reduce the intake of carbohydrates, and the latter is to increase the excretion of carbohydrates. Then, both seem to have a common basis for the function of carbohydrates. In this article, we report a case of T2DM showing improved glycemic variability and depression by the administration of SGLT2 inhibitors.

According to the common statement of the European Association for the Study of Diabetes (EASD) and the American Diabetes Association (ADA), LCD has been recommended for the management of diabetes [20]. LCD is defined as the diet which reduces carbohydrate intake less than $26 \%$ of total daily energy intake. LCD has been reported to have the efficacy of reducing blood glucose in diabetic patients. On the other hand, moderate restriction of carbohydrates (26-45\%) showed no additional effect [20]. Also, LCD can reduce the risk for patients with metabolic syndrome, in which the values of blood

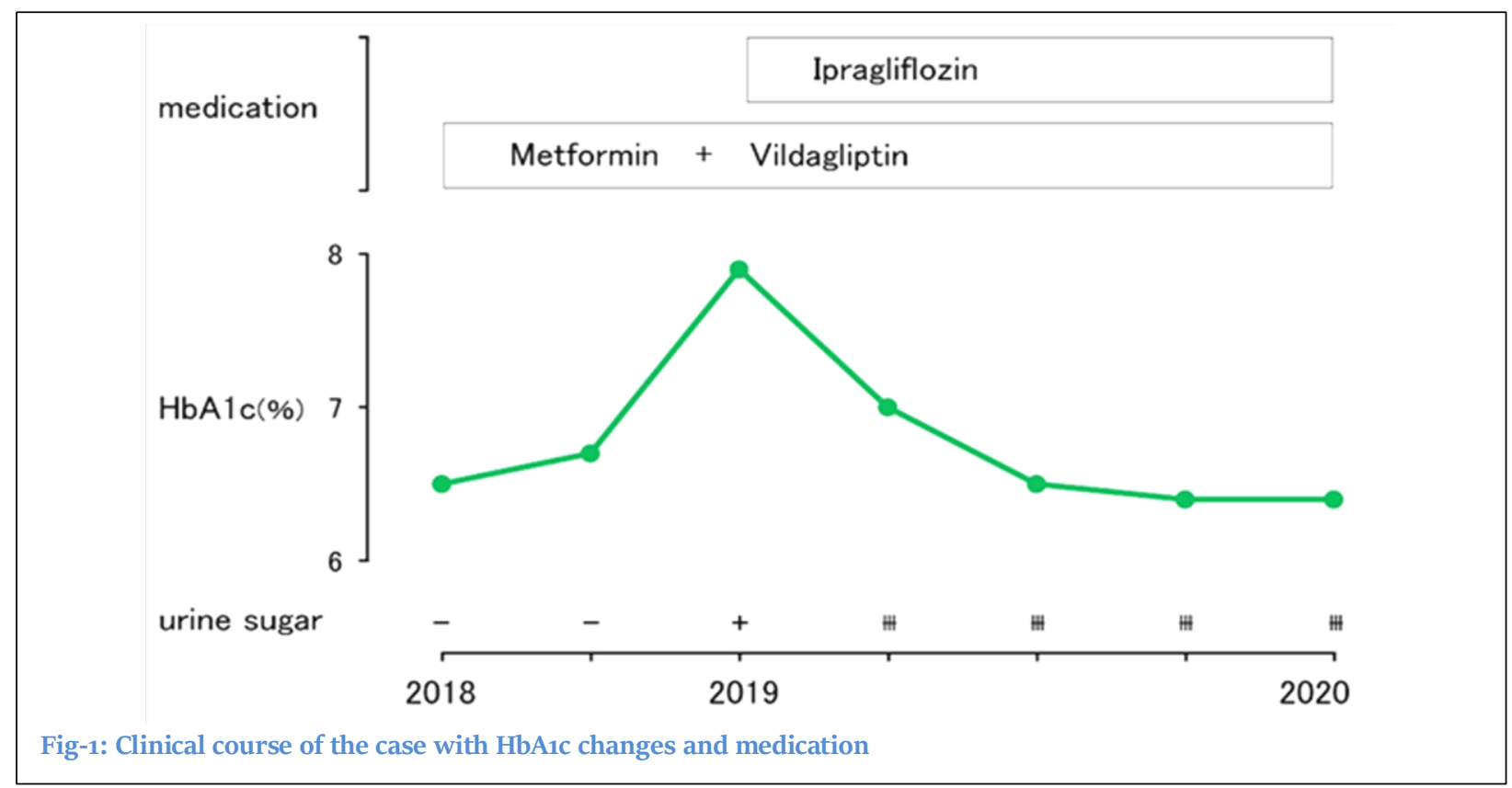


glucose, triglyceride and cholesterol have been reduced [21]

Recent data of the National Health and Nutrition Examination Survey (NHANES) were investigated for the effect of LCD [22]. There were some impressive and equivocal results [20]. The result was that the subjects of the lowest quartile for carbohydrate intake (39-49\% of carbohydrate intake) showed the 50\% elevated risk for cardio- and cerebro- vascular diseases [22]. However, despite the careful nature of their analysis [22], the cut-off for the lowest quartile of carbohydrates considered as LCD is still higher in absolute (200g/day) or relative terms (39-49\% of total energy intake) compared to common LCDs. The archetypical LCD is the ketogenic diet (low carbohydrate/high fat), and ketogenic dieters consume only $10-30$ /day of carbohydrates (10-20\% of total energy) [21].

Other LCDs set a 50g/day carbohydrate intake per day, while moderate carbohydrate restriction allows up to $80-130$ /day (26-45\% of total energy) [20,21]. Therefore, the interpretation of Mazidi et al. [22] should be made with greater caution, since the study may underestimate the effect of a true LCD.

SGLT2 inhibitors have been in focus for their beneficial clinical efficacy. There have been some mega studies about them as follows: i) Canagliflozin and Renal Events in Diabetes with Established Nephropathy Clinical Evaluation (CREDENCE) [23], ii) Canagliflozin cardioVascular Assessment Study (CANVAS) [24], iii) Empagliflozin Cardiovascular Outcome Event Trial in Type 2 Diabetes Mellitus Patients-Removing Excess Glucose (EMPA-REG OUTCOME) study [25] and iv) Dapagliflozin Effect on CardiovascuLAR Events (DECLARE) -TIMI 58 [26].

As to the cardiovascular benefits of SGLT2 inhibitors, 38,723 patients from 4 trials for 2.9 years on average were investigated [27]. As a result, SGLT2 inhibitors could protect against CVD and death in diverse subsets of T2DM patients regardless of the CVD history [27].

One of the SGLT2 inhibitors would be Ipragliflozin
L-Proline. It has been rather prevalent and has been investigated for its efficacy in some studies. There is a STELLA-LONG TERM study, which stands for the Specified drug use resulTs survEy of IpragLifLozin treAtment in type 2 diabetic patients, LONG-TERM [28]. It is a 3-year prospective post-marketing surveillance study, which is continuing on the longterm efficacy and safety of ipragliflozin [29]. Some results were reported concerning clinical effects and adverse drug reactions (ADRs) [30]. Among them, significant reductions were found in $\mathrm{HbA1c}(-0.8 \%)$, fasting plasma glucose $(-31.9 \mathrm{mg} / \mathrm{dL})$, body weight ($2.9 \mathrm{~kg})$, in AST $(-9.0 \mathrm{U} / \mathrm{L})$ and ALT $(-14.7 \mathrm{U} / \mathrm{L})$ [30]). In a short period, liver function was improved in $20.5 \%(543 / 2,648)$ of patients after 3 -month of ipragliflozin in T2DM patients with abnormal liver function [31]. As for the adverse effect of ipragliflozin, there was $0.04-0.18 \%$ of depression as psychiatric disorders, which would be very rare [28].

There was also a ASSIGN-K Study for Ipragloflozin [32]. ASSIGN-K stands for a study of the safety and efficacy of ipragliflozin in the treatment of diabetes in Kanagawa. For 301 patients with T2DM followed 104 weeks, there was the significant reduction of A1c (8.07\% to $7.24 \%)$, fasting blood glucose $(-19.8$ $\mathrm{mg} / \mathrm{dL})$ and postprandial blood glucose $(-29.6 \mathrm{mg} / \mathrm{dL})$. In addition, both of body fat $(-1.87 \mathrm{~kg})$ and fat-free mass $(-1.02 \mathrm{~kg})$ were significantly reduced.

An experiment of ipragliflozin was found for giving a sugar solution to mice [33]. Experiment mice with T2DM was classified into 3 groups, in which they were fed i) ordinary drinking water, ii) water + glucose solution, or iii) water + sucrose solution. As a result, effective dose and response to ipragliflozin did not significantly differ in 3 groups. Then, anti-diabetic and anti-obesity effects of ipragliflozin were not greatly affected by sugar solution intake. Consequently, these results suggest that ipragliflozin would be an effective agent for T2DM patients, who take excessive intake of carbohydrates [33].

Depression has been one of the important complications of diabetes. In order to investigate the relationship between LCD and mental status, T2DM cases were assessed by a questionnaire for taking food 
and by the depression, anxiety, and stress scale [34]. As a result, cases in the highest quartile of LCD score showed a $69 \%$ lower risk of poor sleep, and a $73 \%$ lower risk of anxiety compared with those in the lowest quartile. Consequently, T2DM patients with LCD meals seem to have better sleep conditions and less mental disorders [34].

There was a study of the association between depression in diabetes and treatment types (insulin and/or OHA) [36]. For diabetic patients of 50,774/48,978 (M/F), male subjects showed more depression of significantly higher odds ratio (OR) 1.27 in insulin, OR 1.41 in insulin and OHA, compared to those in only OHA treatment. Female showed a similar tendency, but there were no significant differences with OR 1.17 and 1.35, respectively. Thus, the influence of treatment type to depression seemed to be more in male than in female diabetic patients [35].

The risk of depression in diabetes was studied depending on different OHA [9]. T2DM subjects $(n=40,214)$ were divided into 2 groups. Dep. group has depression $(n=1979)$, and the cont. group has no depression $(n=38,235)$. The adjusted odds ratio (AOR) of the dep. group was 1.39 for female and 1.18 for lower for HbA1c. Between two groups, there was no significant difference in $\alpha$-alpha-glucosidase inhibitors, thiazolidinediones or glinides. In contrast, there was a significant difference (numbers of dep. group vs cont. group) in sulfonylureas (112 vs 3404), DPP-4 inhibitors (54 vs 3731), and SGLT-2 inhibitors (1 vs 378), respectively [9]. Thus, SGLT-2 inhibitors seem to have anti-depression efficacy for diabetic patients.

The case reported in this article has several distinctive features. They included i) depression was present formerly, ii) developed T2DM in the course, iii) worsened diabetic control without apparent triggers, iv) starting of SGLT2 inhibitor Ipragliflozin, v) improvement in glycemic response and depression. At that time, there were no other changes in the diabetic situation or medical agents. Therefore, clinical improvement seemed to be at least in part due to the effect of Ipragliflozin. As the limitation of this study, all relevant factors have not been known or investigated.

In summary, an impressive diabetic case was described in this article. Administration of Ipragliflozin to T2DM with depression has improved glycemic control and depression. The case has been followed up at present and in the future, and various possible factors will be investigated. This report may become a useful reference for diabetes care.

\section{Acknowledgment}

The authors express our gratitude for the cooperation to the patient and also related staff concerning this study.

\section{Conflicts of Interest}

The authors declare no conflict of interest about this report.

\section{References}

[1] Saeedi P, Petersohn I, Salpea P, Malanda B, Karuranga S, Unwin N, Colagiuri S, Guariguata L, Motala AA, Ogurtsova K, Shaw JE, Bright D, Williams R; IDF Diabetes Atlas Committee. Global and regional diabetes prevalence estimates for 2019 and projections for 2030 and 2045: Results from the International Diabetes Federation Diabetes Atlas, 9th edition. Diabetes Res Clin Pract. 2019 Nov;157:107843. [PMID: 31518657]

[2] American Diabetes Association. 9. Pharmacologic Approaches to Glycemic Treatment: Standards of Medical Care in Diabetes-2019. Diabetes Care. 2019 Jan;42(Suppl 1):S9o-S102. [PMID: 30559235]

[3] Qaseem A, Humphrey LL, Sweet DE, Starkey M, Shekelle P; Clinical Guidelines Committee of the American College of Physicians. Oral pharmacologic treatment of type 2 diabetes mellitus: a clinical practice guideline from the American College of Physicians. Ann Intern Med. 2012 Feb 7;156(3):218-31. [PMID: 22312141]

[4] Schwingshackl L, Chaimani A, Hoffmann G, Schwedhelm C, Boeing H. Impact of different dietary approaches on glycemic control and cardiovascular risk factors in patients with type 2 diabetes: a protocol for a systematic review and network meta-analysis. Syst Rev. 2017 Mar 20;6(1):57. [PMID: 28320464] 
[5] Bernstein RK. Dr. Bernstein's Diabetes Solution. Little, Brown and company, New York. 1997.

[6] Shai I, Schwarzfuchs D, Henkin Y, Shahar DR, Witkow S, Greenberg I, Golan R, Fraser D, Bolotin A, Vardi H, Tangi-Rozental O, Zuk-Ramot R, Sarusi B, Brickner D, Schwartz Z, Sheiner E, Marko R, Katorza E, Thiery J, Fiedler GM, Blüher M, Stumvoll M, Stampfer MJ; Dietary Intervention Randomized Controlled Trial (DIRECT) Group. Weight loss with a low-carbohydrate, Mediterranean, or low-fat diet. N Engl J Med. 2008 Jul 17;359(3):229-41. [PMID: 18635428]

[7] Ebe K, Ebe Y, Yokota S, Matsumoto T, Hashimoto M, Sakai Y. Low Carbohydrate diet (LCD) treated for three cases as diabetic diet therapy. Kyoto Medical Association Journal. 2004;51:125-29.

[8] Bando H, Muneta T, Bando M, Yonei Y. Effect of low carbohydrate diet on type 2 diabetic patients and usefulness of M-value. Diabetes Research: Open Journal. 2017 Feb 13;3(1):9-16.

[9] Akimoto H, Tezuka K, Nishida Y, Nakayama T, Takahashi Y, Asai S. Association between use of oral hypoglycemic agents in Japanese patients with type 2 diabetes mellitus and risk of depression: A retrospective cohort study. Pharmacol Res Perspect. 2019 Nov 21;7(6):eoo536. [PMID: 31768258]

[10] Calvín JR, Gaviria AZ, Ríos MM. Prevalence of depression in type 2 diabetes mellitus. Revista Clínica Española (English Edition). 2015 Apr 1;215(3):156-64. [11] Zhang Y, Ting RZ, Yang W, Jia W, Li W, Ji L, Guo X, Kong AP, Wing YK, Luk AO, Sartorius N, Morisky DE, Oldenburg B, Weng J, Chan JC; China Depression in Chinese Patients with Type 2 Diabetes (DD2) Study Group. Depression in Chinese patients with type 2 diabetes: associations with hyperglycemia, hypoglycemia, and poor treatment adherence. J Diabetes. 2015 Nov;7(6):80o-8. [PMID: 25349949]

[12] Wang Y, Lopez JM, Bolge SC, Zhu VJ, Stang PE. Depression among people with type 2 diabetes mellitus, US National Health and Nutrition Examination Survey (NHANES), 2005-2012. BMC Psychiatry. 2016 Apr 5;16:88. [PMID: 27044315]

[13] Ali S, Davies MJ, Taub NA, Stone MA, Khunti K. Prevalence of diagnosed depression in South Asian and white European people with type 1 and type 2 diabetes mellitus in a UK secondary care population. Postgrad Med J. 2009 May;85(1003):238-43. [PMID: 19520874]
[14] Nouwen A, Winkley K, Twisk J, Lloyd CE, Peyrot $\mathrm{M}$, Ismail K, Pouwer F; European Depression in Diabetes (EDID) Research Consortium. Type 2 diabetes mellitus as a risk factor for the onset of depression: a systematic review and meta-analysis. Diabetologia. 2010 Dec;53(12):2480-86. [PMID: 20711716]

[15] Katon W, Pedersen HS, Ribe AR, Fenger-Grøn M, Davydow D, Waldorff FB, Vestergaard M. Effect of depression and diabetes mellitus on the risk for dementia: a national population-based cohort study. JAMA Psychiatry. 2015 Jun;72(6):612-19. [PMID: 25875310]

[16] Hirabayashi N, Hata J, Ohara T, Mukai N, Nagata M, Shibata M, Gotoh S, Furuta Y, Yamashita F, Yoshihara K, Kitazono T, Sudo N, Kiyohara Y, Ninomiya T. Association Between Diabetes and Hippocampal Atrophy in Elderly Japanese: The Hisayama Study. Diabetes Care. 2016 Sep;39(9):154349. [PMID: 27385328]

[17] Bando H. Clinical Influence of Sodium-Glucose Cotransporter 2 (SGLT2) Inhibitors for Cardiovascular and Renal Points of View. Diab Res Open Access. 2020 Jan 30;2(S1):9-13.

[18] Muneta T, Kawaguchi E, Nagai Y, Matsumoto M, Ebe $\mathrm{K}$, Watanabe H, Bando H. Ketone body elevation in placenta, umbilical cord, newborn and mother in normal delivery. Glycative Stress Research. 2016 Sep 30;3(3):133-40.

[19] Ebe K, Bando H, Muneta T, Bando M, Yonei Y. Useful Measurement of Glucose Variability by Flash Glucose Monitoring (FGM) with the Efficacy of Sodium-Glucose Cotransporter 2 (SGLT2) Inhibitor. Diab Res Open Access. 2020 Jan 06;2(S1):1-8.

[20] Davies MJ, D'Alessio DA, Fradkin J, Kernan WN, Mathieu C, Mingrone G, Rossing P, Tsapas A, Wexler DJ, Buse JB. Management of Hyperglycemia in Type 2 Diabetes, 2018. A Consensus Report by the American Diabetes Association (ADA) and the European Association for the Study of Diabetes (EASD). Diabetes Care. 2018 Dec;41(12):2669-701. [PMID: 30291106]

[21] York LW, Puthalapattu S, Wu GY. Nonalcoholic fatty liver disease and low-carbohydrate diets. Annu Rev Nutr. 2009;29:365-79. [PMID: 19575599]

[22] Mazidi M, Katsiki N, Mikhailidis DP, Sattar N, Banach M. Lower carbohydrate diets and all-cause and cause-specific mortality: a population-based cohort study and pooling of prospective studies. Eur Heart J. 
2019 Sep 7;40(34):2870-79. [PMID: 31004146]

[23] Perkovic V, Jardine MJ, Neal B, Bompoint S, Heerspink HJL, Charytan DM, Edwards R, Agarwal R, Bakris G, Bull S, Cannon CP, Capuano G, Chu PL, de Zeeuw D, Greene T, Levin A, Pollock C, Wheeler DC, Yavin Y, Zhang H, Zinman B, Meininger G, Brenner BM, Mahaffey KW; CREDENCE Trial Investigators. Canagliflozin and Renal Outcomes in Type 2 Diabetes and Nephropathy. N Engl J Med. 2019 Jun 13;380(24):2295-306. [PMID: 3099026o]

[24] Neal B, Perkovic V, Mahaffey KW, de Zeeuw D, Fulcher G, Erondu N, Shaw W, Law G, Desai M, Matthews DR; CANVAS Program Collaborative Group. Canagliflozin and Cardiovascular and Renal Events in Type 2 Diabetes. N Engl J Med. 2017 Aug 17;377(7):644-57. [PMID: 286056o8]

[25] Zinman B, Inzucchi SE, Lachin JM, Wanner C, Ferrari R, Fitchett D, Bluhmki E, Hantel S, Kempthorne-Rawson J, Newman J, Johansen OE, Woerle HJ, Broedl UC. Rationale, design, and baseline characteristics of a randomized, placebo-controlled cardiovascular outcome trial of empagliflozin (EMPAREG OUTCOME $\left.{ }^{\mathrm{TM}}\right)$. Cardiovasc Diabetol. 2014 Jun 19;13:102. [PMID: 24943000]

[26] Wiviott SD, Raz I, Bonaca MP, Mosenzon O, Kato ET, Cahn A, Silverman MG, Zelniker TA, Kuder JF, Murphy SA, Bhatt DL, Leiter LA, McGuire DK, Wilding JPH, Ruff CT, Gause-Nilsson IAM, Fredriksson M, Johansson PA, Langkilde AM, Sabatine MS; DECLARETIMI 58 Investigators. Dapagliflozin and Cardiovascular Outcomes in Type 2 Diabetes. N Engl J Med. 2019 Jan 24;380(4):347-57. [PMID: 30415602]

[27] Arnott C, Li Q, Kang A, Neuen BL, Bompoint S, Lam CSP, Rodgers A, Mahaffey KW, Cannon CP, Perkovic V, Jardine MJ, Neal B. Sodium-Glucose Cotransporter 2 Inhibition for the Prevention of Cardiovascular Events in Patients With Type 2 Diabetes Mellitus: A Systematic Review and MetaAnalysis. J Am Heart Assoc. 2020 Feb 4;9(3):e0149o8. [PMID: 31992158]

[28] Nakamura I, Maegawa H, Tobe K, Tabuchi H, Uno S. Safety and efficacy of ipragliflozin in Japanese patients with type 2 diabetes in real-world clinical practice: interim results of the STELLA-LONG TERM post-marketing surveillance study. Expert Opin Pharmacother. 2018 Feb;19(3):189-201. [PMID:
29185822]

[29] Maegawa H, Tobe K, Tabuchi H, Nakamura I. Baseline characteristics and interim (3-month) efficacy and safety data from STELLA-LONG TERM, a longterm post-marketing surveillance study of ipragliflozin in Japanese patients with type 2 diabetes in real-world clinical practice. Expert Opin Pharmacother. 2016 Oct;17(15):1985-94. [PMID: 27463414]

[30] Nakamura I, Maegawa H, Tobe K, Uno S. Safety and Effectiveness of Ipragliflozin for Type 2 Diabetes in Japan: 12-Month Interim Results of the STELLALONG TERM Post-Marketing Surveillance Study. Adv Ther. 2019 Apr;36(4):923-49. [PMID: 30767112]

[31] Tabuchi H, Maegawa H, Tobe K, Nakamura I, Uno S. Effect of ipragliflozin on liver function in Japanese type 2 diabetes mellitus patients: a subgroup analysis of the STELLA-LONG TERM study (3-month interim results). Endocr J. 2019 Jan 28;66(1):31-41. [PMID: 30393249]

[32] Iemitsu K, Kawata T, Iizuka T, Takihata M, Takai M, Nakajima S, Minami N, Umezawa S, Kanamori A, Takeda H, Ito S. Efficacy and safety of ipragliflozin in patients with type 2 diabetes: ASSIGN-K study. J Endocrinol Metab. 2019 Jun 18;9(3):51-62.

[33] Tahara A, Takasu T, Yokono M, Imamura M, Kurosaki E. Antidiabetic and antiobesity effects of SGLT2 inhibitor ipragliflozin in type 2 diabetic mice fed sugar solution. Eur J Pharmacol. 2018 Jan 5;818:545-53. [PMID: 29154936]

[34] Daneshzad E, Keshavarz SA, Qorbani M, Larijani B, Azadbakht L. The association between Low Carbohydrate diet, sleep status, depression, anxiety and stress score. Journal of the Science of Food and Agriculture. 2020 Feb 7.

[35] Lee HJ, Jang J, Lee SA, Oh SS, Park EC. Association between the Type of Diabetes Treatment and Depressive Symptoms among Patients with Diabetes: A Cross-Sectional Study of Korea Community Health Surveys Data, 2011-2016. Int J Environ Res Public Health. 2019 Nov 12;16(22). pii: E4441. [PMID: 31726788]

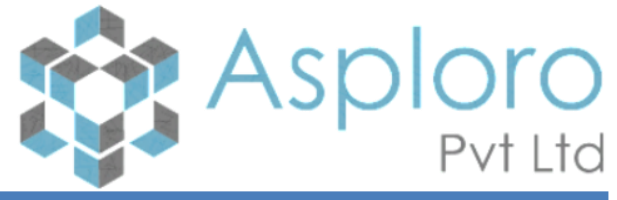

Keywords: Sodium-Glucose Cotransporter-2 (SGLT2) Inhibitor; Ipragliflozin L-Proline; Depression; Oral Hypoglycemic Agents (OHA); Low-Carbohydrate Diet (LCD) 